\section{Chlamydia testing in the UK}

The statement in the commentary article by Skidmore et al. ${ }^{1}$ that "in the UK, the Department of Health has provided funding for all National Health Service laboratories to adopt [nucleic acid amplification] tests", for the detection of Chlamydia trachomatis, seems to be based on treating the terms England and UK as synonymous. While that might be an understandable mistake, it is still a mistake.

In 2003, the Department of Health in England provided $£ 8000000$ to support laboratories to change from the inaccurate but cheap enzyme-linked immunoassay tests (ELISAs) for $C$. trachomatis to the accurate but expensive nucleic acid amplification tests (NAATs) ${ }^{2}$ Four years later, the Chief Medical Officer (CMO) in Wales has taken a similar view that testing platforms for the detection of genital C. trachomatis other than NAATs are suboptimal. Unfortunately, although the CMO estimates that it will only cost $£ 150000$ to extend the use of NAATs across the whole of Wales and states that "service commissioners and providers would be highly vulnerable to criticism if what is now the recognised optimal testing method was not used", I do not think that any funding has been provided to the laboratories in Wales ${ }^{3}$

Here in Mid Wales we are still using an ELISA to detect, as the CMO estimates, $70 \%$ of female and 54\% of male genital C. trachomatis infection $^{3}$ and, as I write this letter, we have but 7 weeks to comply with the CMO's expectation that all individuals tested for chlamydia infection in Wales will be offered the NAAT by 1 December 2007.3

\section{Peter Watson, DFFP, FRCP}

Consultant in Genitourinary Medicine,

Ceredigion and Mid Wales NHS Trust,

Bronglais General Hospital, Aberystwyth, UK

E-mail:peter.watson@ceredigion-

tr.wales.nhs.uk

\section{References}

Skidmore S, Randall S, Mallinson H. Testing for Chlamydia trachomatis: self-test or laboratory-based diagnosis? J Fam Plann Reprod Health Care 2007; 33. 231-232.

2 Department of Health. Use of Sub-optimal Testing Platforms for the Detection of Genital Chlamydia trachomatis Infection in England. January 2003. http://www.dh.gov.uk/en/Publicationsandstatistics/Pub lications/PublicationsPolicyAndGuidance/DH 407334 6 [Accessed 17 October 2007].

3 Jewell T. Use of sub-optimal testing platforms for the detection of genital Chlamydia trachomatis infection in Wales (Letter to Chief Executives and Medical Directors of LHBs and NHS Trusts). CMO (2007)4. 4 July 2007. http://new.wales.gov.uk/docrepos/40371/

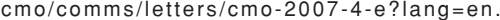
[Accessed 17 October 2007].

\section{Implanon ${ }^{\circledR}$ failure and}

\section{antiretroviral therapy}

We read the case report by Matiluko et al. ${ }^{1}$ in the October 2007 issue of the Journal with interest. Efavirenz, a non-nucleoside reverse transcriptase inhibitor (NNRTI), is known to have complex interactions with cytochrome P450 enzymes, being both an inhibitor and an inducer of this system. Characteristically it has been the protease inhibitor (PI) class of antiretroviral therapy (ART) that has been associated with contraceptive failures. Nonetheless, both commercially available NNRTIs (efavirenz and nevirapine) are associated with reduced in vivo levels of ethinylestradiol and progestogens. ${ }^{2}$ In the reported case, the patient was receiving an NNRTI-based regime and had begun having regular menstrual cycles after almost 2 years of amenorrhoea following Implanon ${ }^{\circledR}$ insertion. There is no evidence for the use of Implanon in HIV-positive patients, specifically those receiving ART, although results are awaited from a USA study which has fully recruited and is looking at the impact of lopinavir/ritonavir (Kaletra ${ }^{\circledR}$, a PI used as ART) on Implanon efficacy (Laura Waters, personal communication,
2007). In our personal opinion, HIV-infected patients who wish to continue using Implanon after appropriate counselling regarding risks and benefits should be advised not only to also use a concomitant barrier method, but also to consider earlier replacement (e.g. after 2 years if regular menses commence following a period of amenorrhoea). This would be consistent with the advice given currently to women weighing more than $70 \mathrm{~kg}$, for example. ${ }^{3}$ Whilst we cannot deny that Implanon is currently not an ideal contraceptive method in terms of pharmacokinetics or STI prevention in our HIVpositive population, there remain significant advantages to the method in HIV-positive women. It is a method over which women have control and which is long acting, thus decreasing the time spent by women attending health care services. It is also a method that may be used by women needing to conceal contraception from their male partners.

It is difficult to say in the case presented if the drug interactions were truly to blame for Implanon failure. In the absence of good pharmacokinetic data or studies regarding the combined use of ART and Implanon it would seem best to continue to recommend othe methods however. With appropriate counselling it may also be sensible to advise women wishing to continue with this method to consider earlier Implanon replacement, especially if regular menstrual cycles commence before the normal 3 year replacement date.

\section{Tristan J Barber, MRCP, DFFP}

Specialist Registrar in GUM/HIV, Chelsea and Westminster NHS Foundation Trust,

London, UK

E-mail:tristan.barber@chelwest.nhs.uk

Laura Waters, MRCP, DFFP

Locum Consultant in GUM/HIV, Imperial

College Healthcare NHS Trust, St Mary's Campus, London, UK

\section{References}

Matiluko AA, Soundarajan L, Hogston P. Early contraceptive failure of Implanon ${ }^{\circledR}$ in an HIVseropositive patient on triple antiretroviral therapy with zidovudine, lamivudine and efavirenz I Fam Plann Reprod Health Care 2007; 33: 277-278.

2 Faculty of Family Planning and Reproductive Health Care Clinical Effectiveness Unit. FFPRHC Guidance (April 2005). Drug interactions with hormona (April 2005). Drug interactions with hormonal 31: 139-151.

3 Faculty of Family Planning and Reproductive Health Care Clinical Effectiveness Unit. Members Enquiry Response (Enquiry Reference: 1072). May 2005. http://www.ffprhc.org.uk/admin/uploads/No1072.pd [Accessed 20 October 2007].

\section{Reply}

We thank Drs Barber and Waters for their interes in, and letter about, our recent case report. ${ }^{1}$ At no point in our case report did we unequivocally state that Implanon ${ }^{\circledR}$ failure was due to the patient's antiretroviral therapy (ART). We only hypothesised on the connection between the ART and the early failure of Implanon as the patient was not on any other medication except for Becotide ${ }^{\circledR}$, which to our knowledge has no liver enzyme-inducing effect.

The case was reported to highlight the potential reduction in the effective duration of contraceptive efficacy of Implanon in the presence of concomitant administration of drugs with potential for liver enzyme induction (i.e. ART)

We would, however, agree with Drs Barber and Waters that pending studies on the use of Implanon in HIV-positive patients on ART, its use should be with appropriate counselling regarding risks and benefits and concomitant use of barrie method for obvious reasons.

Although the patient in the reported case was amenorrhoeic for almost 2 years, we would suggest that consideration for earlier replacement or alternative contraception should be sought at the nearest family planning clinic as soon as periods are resumed after any period of amenorrhoea following insertion, since resumption of regular periods following post-insertion amenorrhoea may vary from one individual to another based on many other factors such as weight, use of other medications, and so on.

A A Matiluko, MBBS, MRCOG

Senior Registrar, Department of Obstetrics and Gynaecology, North Hants Hospital, Basingstoke, UK

E-mail: tbs8996@matil.freeserve.co.uk

Reference

Matiluko AA, Soundarajan L, Hogston P. Early contraceptive failure of Implanon ${ }^{\circledR}$ in an HIVseropositive patient on triple antiretroviral therapy with zidovudine, lamivudine and efavirenz. J Fam Plann Reprod Health Care 2007; 33: 277-278.

\section{Difficult IUD insertions}

After approximately 25 years' experience of fitting intrauterine devices (IUDs) in general practice, I have of late found myself pondering why slowly the process seems to become increasingly difficult. Rather than becoming easier the more experience I gain, IUD fits seem to become more problematic. Surely not what one would expect?

And then the penny dropped. Back in the 1980s, the standard IUD patient would be in her 30 s with two or three vaginal deliveries behind her who had lost all her inhibitions about gynaecological procedures years before. Today's IUD patient may have had perhaps one baby by Caesarean section, or be nulliparous, in her early $40 \mathrm{~s}$ and requesting a Mirena ${ }^{\circledR}$ for menstrual problems; neither individual will be the easiest to fit with an IUD and neither will be well prepared for the indignity and discomfort that inevitably accompanies the procedure. Would other experienced practitioners concur with this, or am I just making excuses?

Because if I'm not making excuses, we need better means of handling the pain of an IUD insertion, dilators, sounds and progestogen devices that are suitable for nullips, tenaculae that cause minimal pain, and so on. And concern for the trainees who have to learn in this environment

All sensible comments are very welcome.

Isabel B Draper, MRCGP, FFFP

General Practitioner, Whitehall Medical

Practice, Rugby, UK

E-mail:IBD@doctors.org.uk

\section{Training for the LOC IUT}

As a practising instructing doctor, I disagree with the arguments put forward by Dr Devonald in her letter in the October 2007 issue of this journal ${ }^{1}$ for considering altering the criteria for this qualification.

Within our practice we actively promote the use of intrauterine devices (IUDs) and the intrauterine system (IUS) as long-acting reversible contraceptive (LARC) methods in suitable women. All women requesting an intrauterine method are seen at an initial counselling and assessment session to discuss their contraceptive needs and they are informed about all their long-term options. We find that this allows women to be informed users and improves compliance with their chosen method.

In 2005-2006, I fitted 162 copper IUDs, which were mainly the 'gold standard' TCu380A (T-Safe $380 A^{\circledR}$ ) and 57 Mirena ${ }^{\circledR}$ devices. Last year (i.e. in 2006-2007) this changed to 181 IUDs and 43 Mirenas. Of these, one woman had to change to Mirena due to heavy periods but the rest have reported no problems with pain or bleeding. Conversely, one Mirena had to be removed within a week as the woman did not like the idea of having a hormonal coil. She had originally been counselled by her own general practitioner (GP). 